\title{
Avaliação de Curso de Graduação segundo egressos
}

\author{
COLLEGE PROGRAM EVALUATION ACCORDING TO GRADUATES
}

\section{EVALUACIÓN DEL CURSO DE GRADUACIÓN SEGÚN LOS EGRESADOS}

\author{
Maria Dyrce Dias Meira1, Paulina Kurcgant ${ }^{2}$
}

\begin{abstract}
RESUMO
O egresso da graduação enfrenta, no seu cotidiano, situações complexas que o levam a confrontar as competências desenvolvidas durante o curso com as requeridas no exercício profissional. Tal vivência permiteIhe avaliar a adequação da estrutura pedagógica do curso e resgatar aspectos intervenientes desse processo. Este texto aborda a Avaliação de Cursos de Graduação, resgatando conceitos no campo da Avaliação Educacional; descreve as práticas desenvolvidas no Brasil dirigidas à Avaliação Institucional no âmbito da graduação e apresenta pesquisas relativas à avaliação de cursos, tendo a perspectiva do egresso como indicador. Foram utilizadas as seguintes palavras-chave: egressos, indicadores, avaliação e graduação, disponíveis nas bases de dados: PeriEnf, BDEnf, LILACS e no banco de dados DEDALUS. A análise das pesquisas encontradas ressalta a importância de se considerar a opinião dos egressos na adequação de propostas curriculares com vistas à concretização de um processo educacional com características emancipatórias e transformadoras.
\end{abstract}

\section{DESCRITORES}

Educação em enfermagem. Estudantes de enfermagem. Avaliação.

\begin{abstract}
Every day, college graduates face complex situations that make them check skills developed during the course in comparison with the skills needed at the professional level. This experience helps them evaluate the adequacy of the course's teaching structure and recover intervening aspects of this process. This text discusses the Evaluation of College Courses, recovering concepts in the field of Education Evaluation; describes the practices developed in Brazil, directed towards course evaluation, based on the graduate's perspective. The following descriptors were used: college graduates, indicators, evaluation and graduation available in the databases: PeriEnf, BDEnf, LILACS and DEDALUS. The analysis of the surveyed studies highlights the need to consider the opinion of college graduates in the curriculum proposals with a view to implementing an educational process with emancipating and transforming characteristics.
\end{abstract}

\section{KEY WORDS}

Education, nursing.

Students, nursing.

Evaluation.

\section{RESUMEN}

El egresado de los cursos universitarios de enfermería enfrenta, en lo cotidiano, situaciones complejas que lo llevan a confrontar las competencias obtenidas durante el curso con las requeridas en el ejercicio profesional. Esta vivencia le permite evaluar la adecuación de la estructura pedagógica del curso y rescatar aspectos que intervienen, en ese proceso. Este texto aborda la Evaluación de Cursos Universitarios rescatando conceptos en el campo de la Evaluación Educacional; describe las prácticas desarrolladas en Brasil, dirigidas a Evaluar la Institución en el ámbito de la formación y presenta investigaciones relacionadas a la evaluación de cursos teniendo, como indicador, la perspectiva del egresado. Fueron utilizadas las palabras claves: egresados, indicadores, evaluación y graduación, disponibles en las bases de datos: PeriEnf, BDEnf, LILACS y en el banco de datos DEDALUS. el análisis de las investigaciones encontradas destaca la importancia de considerar la opinión de los egresados en la adecuación de propuestas curriculares con el objetivo de concretizar un proceso educacional con características emancipadoras y transformadoras.

\section{DESCRIPTORES}

Educación en enfermería.

Estudiantes de enfermería. Evaluación.

${ }^{1}$ Doutoranda do Programa de Pós Graduação em Enfermagem da Escola de Enfermagem da USP. Docente do Curso de Enfermagem do Centro Universitário Adventista de São Paulo. São Paulo, SP, Brasil. dyrcem@yahoo.com.br ${ }^{2}$ Professora doutora. Docente do Programa de Pós Graduação em Enfermagem da Escola de Enfermagem da USP. São Paulo, SP, Brasil. pkurcg@usp.br 


\section{INTRODUÇÃO}

A Avaliação Educacional, cada vez mais se configura como um campo em expansão no Brasil, considerando-se o crescente interesse em sistematizar a avaliação como meio de monitoramento e implementação de políticas no ensino superior. É também Considerada como prática que possibilita a transparência das realizações institucionais tanto para a comunidade universitária como para a sociedade. Considera-se ainda que: uma proposta de avaliação tem que estar relacionada com o objeto ao qual se dirige; a avaliação se concretiza dependendo dos valores e interesses que os sujeitos envolvidos têm e

a avaliação deve possibilitar, à comunidade acadêmica, analisar os processos contraditórios que permeiam a vida universitária e procurar, de fato, dar uma dinâmica ao processo de avaliação que contemple uma visão de totalidade da problemática educacional(1).

Dentre as diferentes possibilidades de avaliação de cursos universitários, registra-se a alternativa de averiguar a opinião do egresso quando já exercendo atividades profissionais. Esta é uma das dimensões que possibilita a visão das transformações que ocorrem, no aluno, devido à influência exercida pelo currículo.

O egresso enfrenta no seu cotidiano de trabalho situações complexas, que o levam a confrontar as competências desenvolvidas, durante o curso, com as requeridas no exercício profissional. Pode, a partir daí, avaliar a adequação da estrutura pedagógica do curso que foi vivenciado, bem como os aspectos intervenientes no processo de formação acadêmica.

Nesta direção este texto objetiva: apresentar uma síntese dos conceitos abordados no campo da Avaliação Educacional $^{(2)}$; descrever as práticas desenvolvidas no Brasil para a Avaliação Institucional no âmbito dos cursos de graduação e apresentar pesquisas relativas à avaliação de cursos tendo, como indicador, a perspectiva do egresso buscando apreender os aspectos considerados por eles importantes, no seu processo formativo.

O método utilizado foi o de revisão bibliográfica e uma vez que os descritores padronizados (Avaliação, Educação em Enfermagem, Estudantes de Enfermagem) restringiram os resultados da busca, foram utilizadas as palavras chaves: egressos, indicadores, avaliação e graduação nas bases de dados: PeriEnf, BDEnf, LILACS e no banco de dados DEDALUS. Pelo fato das pesquisas encontradas sobre avaliação na perspectiva do egresso na área de enfermagem serem poucas, para subsidiar a análise, foram apresentados estudos que abrangem outras áreas da graduação.

\section{CONCEITUAÇÃO HISTÓRICA}

O campo da avaliação educacional tem sido objeto de estudo de vários autores que a partir dos anos 50 , buscam novas conceituações de práticas avaliativas coerentes com as concepções pedagógicas. Tyler foi um dos primeiros teóricos a buscar um aprofundamento nesse campo tendo contribuído com estudos sobre avaliação por objetivos e com a diferenciação conceitual sobre avaliação e medida. Baseado no conceito de que educar consiste na mudança de padrões de comportamento. Tyler atribuiu, à escola, a responsabilidade de verificar sua eficiência, através da avaliação. Considera também que a avaliação proporciona subsídios para uma análise crítica que possibilita a reformulação e o aprimoramento da programação curricular. Preocupase com o julgamento da eficiência do currículo, identificando a avaliação como o processo de investigação de valores que visa o aperfeiçoamento do sistema educacional ${ }^{(2)}$.

Na concepção de Cronbach, a avaliação tem por finalidade fazer não apenas um julgamento final, mas oferecer meios para o aprimoramento de currículos e apresenta quatro aspectos considerados de importância: a associação entre avaliação e o processo de tomada de decisão; os diferentes papéis da avaliação educacional; o desempenho do estudante como critério de avaliação de cursos e algumas técnicas de medida à disposição do avaliador educacional(2).

Stake defende a idéia de que a avaliação não deve ter um caráter meramente episódico, devendo ser calcada na compreensão de todo o processo que diz respeito ao programa educacional tendo como base o levantamento de dados fundamentados na realidade. Suas idéias deram origem à avaliação responsiva e destaca os aspectos formal e informal da avaliação trazendo importante contribuição à metodologia do estudo de caso ao considerar que este deve ser fundamentado em uma observação reflexiva e interpretativa ${ }^{(2)}$.

Para Scriven a avaliação educacional desempenha vários papéis, mas possui um único objetivo que é o de determinar o valor ou o mérito do que está sendo avaliado. $\mathrm{O}$ objetivo é a resposta aos problemas e os papéis são as várias possibilidades de uso desta resposta. Para este autor, Não existe diferença entre avaliação formativa e somativa, pois ambas visam determinar o valor de uma entidade em particular. Salienta ainda que a diferença entre elas esta no timing em que são realizadas, para o que se destinam e no uso que se faz dos resultados. Tudo depende da perspectiva em que se situa quem faz a análise ${ }^{(2)}$.

Stufflebeam a partir dos anos 70 define avaliação como um processo para descrever, obter e processar informação útil para julgar decisões alternativas. Destaca três aspectos indispensáveis para a compreensão do seu modelo: a avaliação como um processo sistemático e contínuo; a avaliação como base para elaborar questões e buscar informações que respondam, de forma relevante, a essas questões e, por fim, propõe que a avaliação deve favorecer a tomada de decisão dos gestores. Apresenta o modelo CIPP (Contexto, Insumos, Processo e Produto) que tem como ponto central aprimorar e não provar ${ }^{(2)}$. 
Estes conceitos foram incorporados aos processos avaliativos e de alguma forma influenciaram a implementação dos sistemas de avaliação educacional praticados no Brasil voltados ao ensino superior no decorrer dos anos.

\section{AVALIAÇÃO INSTITUCIONAL NO ENSINO SUPERIOR NO BRASIL}

Considerando que a avaliação deve diagnosticar pontos críticos do programa de ensino para oportunizar as correções necessárias na proposta educativa são registradas a seguir, algumas iniciativas no campo da avaliação do ensino superior no Brasil.

Na década de 90, foi criado o Programa de Apoio Institucional das Universidades Brasileiras (PAIUB) que concebeu a avaliação como um processo contínuo de aperfeiçoamento acadêmico para o planejamento da gestão universitária, para a prestação de contas à sociedade e como um processo criativo de autocrítica ${ }^{(3)}$.

O PAIUB, apesar de fortemente influenciado por modelos internacionais, projetava a avaliação, numa perspectiva bastante progressista e emancipatória, adequada ao sistema educacional brasileiro, visando a melhoria da qualidade pedagógica, científica e gestora, sem abrir mão da autonomia. Se praticada a partir da realidade social, esta proposta permitiria visualizar as peculiaridades de cada instituição e poderia ser considerada como referência para uma política de avaliação das Instituições de Ensino Superior (IES).

Após a publicação da Lei no 9.131/95, que trata da criação do Conselho Nacional de Educação e institui o Exame Nacional de Curso e, principalmente, a partir da Lei no 9394/ 96 que estabelece as diretrizes e bases da Educação Nacional ${ }^{(4)}$, a avaliação institucional tornou-se uma prioridade para o Ministério da Educação e Cultura (MEC) que passa a assumir um papel controlador, tendo de um lado o Estado e do outro as Instituições de Ensino, e como ponto comum, a busca da qualidade. Neste contexto o papel das escolas era o de realizadoras da missão científica e social, de promotoras do auto-conhecimento e de tomada de decisão, enquanto, o papel do Estado era o de garantir o cumprimento de normas, requisitos legais, metas, ranking e credenciamentos.

A avaliação segundo esta proposta deveria acontecer em quatro níveis: no desempenho global do sistema educacional utilizando indicadores por região segundo áreas do conhecimento e tipo de instituição; no desempenho individual das IES em todos os níveis e modalidades de ensino, pesquisa e extensão; na avaliação dos cursos pelas condições estruturais e resultado no Exame Nacional de Cursos, conhecido como provão; e na avaliação da pós-graduação por área do conhecimento(4). Alguns autores referem que a realização destes exames reduziu a atividade avaliativa ao procedimento de medida ou quantificação de resultados, surgindo críticas a este sistema de avaliação, entre as quais, o incentivo à competitividade, provocado pelo estabelecimento de ranking das instituições e o uso dos resultados do provão, como critério para a liberação de recursos financeiros ${ }^{(5)}$.

Contrapondo-se a este modelo avaliativo, Dias Sobrinho sugeriu uma avaliação educativa que deveria ser formativa, democrática, participativa, global e contínua, com ênfase qualitativa, e ter: flexibilidade, credibilidade e legitimidade, institucionalidade e continuidade. Para ele a avaliação deveria ser contemplada nos níveis nacional e institucional e ser considerada em três dimensões essenciais: auto-avaliação, avaliação externa com a reavaliação e a meta-avaliação( ${ }^{(6)}$. As contribuições deste autor foram fundamentais para direcionar as propostas de um novo Sistema de Avaliação.

A partir de 2004, com o propósito de alargar as fronteiras da Avaliação Educacional, o MEC instituiu o Sistema Nacional de Avaliação da Educação Superior (SINAES). Fundamentado em uma concepção predominantemente formativa ${ }^{(7)}$. Esse sistema contempla de forma integrada a avaliação das instituições, dos cursos e do desempenho dos estudantes, permitindo assim que a própria instituição verifique sua qualidade e sua responsabilização social;

A abrangência desta proposta dá, à avaliação, um caráter sistêmico, por integrar os espaços, os momentos e os diferentes instrumentos de avaliação em torno de uma concepção global única(8).

Entre as dez dimensões que o SINAES avalia, a nona dimensão faz referência à Política de atendimento a estudantes e egressos. O manual de orientações para a operacionalização da auto-avaliação da IES, concernente a esta dimensão, apresenta como núcleo básico e comum, a inserção profissional dos egressos e a participação dos egressos na vida da Instituição. Este manual orienta para que seja observado, na IES, se existem dados e indicadores para avaliar esta dimensão, como pesquisas ou estudos sobre os egressos e/ou empregadores dos mesmos ${ }^{(9)}$.

\section{EGRESSO COMO INDICADOR DA AVALIAÇÃO INSTITUCIONAL}

Na literatura analisada foram encontradas poucas referências que evidenciam a percepção de egressos como indicador de avaliação institucional. Os estudos realizados buscam apreender os aspectos considerados importantes, pelo egresso, no seu processo formativo. A seguir serão apresentados resultados obtidos, por algumas escolas, que empreenderam pesquisas nesta direção.

A Universidade Federal do Ceará (UFC) desenvolveu uma pesquisa com egressos graduados em 2003 e 2004, com os objetivos de analisar o atendimento aos discentes e aos egressos dos cursos de graduação e verificar a contribuição do currículo do curso no atendimento das necessidades profissionais. Participaram do estudo cento e um sujeitos, provenientes de diversas áreas incluindo a enfermagem. Foi aplicado um questionário estruturado que possi- 
bilitou constatar que $72 \%$ dos egressos estavam trabalhando na sua área de formação e $88 \%$ necessitavam buscar novos conhecimentos para enriquecer sua formação. Quanto à contribuição do currículo do curso, no atendimento das necessidades profissionais, $60,4 \%$ revelaram considerála inadequada ao exercício da profissão(10).

Outra pesquisa sobre a prática da Avaliação Institucional contemplando a 9a dimensão do SINAES foi realizada pelo Centro Federal de Educação Tecnológica da Bahia. Nessa pesquisa foram investigados 17 egressos dos cursos de Administração e Engenharia, cujo instrumento adotado buscava a representação dos egressos de forma abrangente. Os resultados foram apresentados em tabelas e gráficos, com demonstrativos percentuais dos principais indicadores como: grau de satisfação dos egressos em relação ao curso, atividades de pesquisa, estágios, crescimento como cidadão, infra-estrutura e imagem da escola ${ }^{(11)}$.

As iniciativas das duas universidades consideraram os critérios de avaliação institucional e evidenciaram a importância de um processo avaliativo, segundo a percepção do egresso.

Um estudo realizado no Centro de Graduação em Enfermagem da Faculdade de Medicina do Triângulo Mineiro (CGE-FMTM) utilizando uma abordagem qualiquantitativa, pesquisou 108 egressos formados nos anos de 1992 a 1999, com o objetivo de: estudar o processo de formação em enfermagem segundo a opinião de egressos; verificar sua inserção no mercado de trabalho e obter sugestões para melhoria do currículo do curso ${ }^{(12)}$. Os resultados desta pesquisa mostraram que $37 \%$ dos egressos estavam inseridos na área hospitalar e $24 \%$ em saúde coletiva. Com relação à escoIha da profissão $76,4 \%$ dos egressos reconheciam ter acertado na opção que fizeram. Quanto ao processo de formação, 83,8\% optariam por estudar, novamente, na mesma instituição, por reconhecerem que o curso contribuiu de forma efetiva para a sua formação e que as disciplinas práticas ajudaram na escolha da área de atuação. Os egressos apresentaram, como sugestões para a melhoria da qualidade de ensino, que: as disciplinas fossem ministradas com conteúdos integrados; houvesse maior tempo de estágio e residência obrigatória; fosse dado maior enfoque aos programas da saúde da família; fossem feitos mais investimentos em pesquisas de enfermagem; houvesse maior intercâmbio acadêmico com a população e que fossem promovidas palestras e jornadas com a participação dos egressos ${ }^{(12)}$.

O grupo de ensino do curso de graduação em enfermagem da Universidade Federal de Santa Catarina (UFSC) desenvolveu um estudo onde analisou qualiquantitativamente, a percepção de treze egressos inseridos em diversas instituições de saúde em Florianópolis. Os resultados apontaram como problemas relacionados ao currículo: tempo insuficiente para as experiências práticas; falta de integração entre as fases do curso; divergência entre o papel do enfermeiro focado no curso e o esperado pelos empregadores; satisfação do egresso em ser enfermeiro e insatisfação quanto ao papel desempenhado, salário e reconhecimento no mercado. Apontam, ainda, as contradições entre o discurso e a prática e entre a visão de integralidade do ser humano e a formação não contextualizada. Segundo a visão das autoras, este trabalho contribuiu para uma reflexão sobre o mundo acadêmico e a realidade profissional|(13).

Docentes da Faculdade de Medicina de São José do Rio Preto (FAMERP) desenvolveram uma pesquisa junto aos egressos das três primeiras turmas de enfermagem graduados até 1996, com o propósito de investigar a sua inserção no mercado de trabalho como parâmetro para a avaliação da qualidade do ensino. Para isso aplicaram um questionário com perguntas abertas e fechadas a 59 egressos. Na percepção das autoras o estudo oportunizou a elaboração de propostas para estabelecer maiores vínculos entre a prática e a teoria, e assim enriquecer o ensino de graduação(14).

Outra pesquisa realizada por docentes da Universidade Estadual do Oeste do Paraná apresentou resultados que subsidiaram a construção de um novo Projeto Político Pedagógico (PPP), que passou a vigorar em 2003. As autoras fizeram uma retrospectiva do processo e se incluíram em dois grupos de trabalho: um grupo que ficou responsável por fazer um resgate conceitual dos valores que norteiam a prática da enfermagem e outro por elaborar um diagnóstico a partir da visão dos acadêmicos, docentes, egressos e profissionais dos campos de estágios. O relatório da pesquisa não menciona o instrumento nem os resultados obtidos a partir da visão dos egressos, mas as autoras admitem que a pesquisa possibilitou a reformulação do PPP do curso no sentido de atender às diretrizes curriculares nacionais e também às demandas reveladas pelo diagnóstico realizado ${ }^{(15)}$.

Merece destaque, pela sua amplitude e abrangência, um projeto de pesquisa que está sendo desenvolvido por docentes da Faculdade de Educação da USP, sobre o destino profissional dos graduados da USP(16). A finalidade deste estudo é a de subsidiar o aprimoramento da gestão acadêmica e melhorar a eficiência e eficácia dos cursos de graduação. Apresenta como objetivos: desenvolver estudos sobre o perfil dos formados nos Cursos de Graduação da USP; conhecer a atividade profissional atual e trajetória ocupacional dos egressos; identificar sua apreciação sobre a formação possibilitada pela universidade e buscar compreender possíveis variáveis intervenientes nas suas escolhas e destinos ocupacionais.

O referido projeto propõe o levantamento de dados em três cursos, da área de Humanas, Exatas e Biológicas com a finalidade de implantar um sistema de acompanhamento de ex-alunos, como uma prática usual. Prevê o delineamento e implementação de uma metodologia de avaliação que incor- 
pore, ao debate, o papel social da universidade, tanto no que diz respeito ao público interno e externo, quanto ao destino profissional de seus egressos. A pesquisa proposta junto aos egressos poderá trazer contribuições valiosas para as IES, por possibilitar a visualização de aspectos relevantes tanto para o processo avaliativo como para o processo educativo.

\section{CONSIDERAÇÕES FINAIS}

Os conceitos apresentados permitiram compreender a importância da avaliação educacional, sistematizada de forma a agregar melhorias ao processo educacional e a incorporar o diálogo entre os atores deste processo incluindo, para tanto, a participação dos egressos.

A trajetória seguida pelos articuladores da política de avaliação para o Ensino Superior no Brasil retrata um movimento crescente no sentido de garantir um ensino de qualidade, atrelado a um Sistema de Avaliação capaz de desencadear

\section{REFERÊNCIAS}

1. Amorim A, Sousa SMZL. Avaliação institucional: definições e posicionamentos. Est Aval Educ. 1990;(1):9-12.

2. Vianna HM. Avaliação educacional. São Paulo: Ibrasa; 2000.

3. Ristoff DI. Algumas definições sobre avaliação. In: Dias Sobrinho J, Ristoff DI, organizadores. Avaliação e compromisso público: a educação superior em debate. Florianópolis: Insular; 2003. p. 21-33.

4. Brasil. Lei n. 9.394, de 20 de dezembro de 1996. Estabelece as Diretrizes e Bases da Educação Nacional (LDB). Diário Oficial da União, Brasília, 23 dez. 1996. Seção 1, p. 27833-41.

5. Sousa SMZ, Freitas DNT. Políticas de avaliação e gestão educacional: Brasil, década de 1990 aos dias atuais. Educ Rev. 2004;(40):165-86.

6. Dias Sobrinho J. Avaliação da educação superior, regulação e emancipação. In: Dias Sobrinho J, Ristoff DI, organizadores. Avaliação e compromisso público: a educação superior em debate. Florianópolis: Insular; 2003. p. 42-52.

7. Brasil. Ministério da Educação. Comissão Nacional de Avaliação da Educação Superior (CONAES). Instituto Nacional de Estudos e Pesquisas Educacionais Anísio Teixeira (INEP). Avaliação externa de instituições de educação superior: diretrizes e instrumento. Brasília; 2005.

8. Brasil. Ministério da Educação. Sistema Nacional de Avaliação da Educação Superior (SINAES). Da concepção à regulamentação. 2a ed. Brasília: INEP; 2004.

9. Brasil. Ministério da Educação. Comissão Nacional de Avaliação da Educação Superior (CONAES). Sistema Nacional de Avaliação da Educação Superior (SINAES). Orientações gerais para o roteiro da auto-avaliação das instituições. Brasília: INEP; 2004. as transformações demandadas pela sociedade. Evidencia, também, a importância de se considerar a percepção do egresso, como um indicador efetivo para a avaliação institucional.

As pesquisas apresentadas, na área da enfermagem, apesar de um quantitativo restrito, demonstram a importante contribuição dos egressos ao avaliarem o processo formativo por eles vivenciado. Apontam como destaques: a adequação do currículo às necessidades da formação profissional; maior investimento em pesquisas; intercâmbio acadêmico com a comunidade envolvendo projetos de extensão universitária; maior integração entre teoria e prática e a necessidade de aumentar o tempo destinado aos estágios.

Este estudo possibilitou compreender que os processos avaliativos carregam um potencial de fazer acontecer e de motivar transformações e que a opinião dos egressos sobre a sua formação é fundamental na concretização de um sistema de avaliação que consolide um processo educativo com características emancipatória e transformadora.

10. Universidade Federal do Ceará (UFC). Dimensão nove: políticas de atendimento dos estudantes e de acompanhamento dos egressos da UFC [texto na Internet]. Fortaleza; 2006. [acesso 2006 jul. 25]. Disponível em: http://www.ufc.br/_files/ conhecaaufc/avaliacao/d9_egressos.pdf

11. Centro Federal de Educação Tecnológica da Bahia (CEFET-BA). Relatório de auto-avaliação institucional do CEFET-BA: etapa educação superior [texto na Internet]. Salvador: CPA; 2006. [citado 2006 jul. 25]. Disponível em: http://www.cefetba.br/ cpa/downloads/Rel_Avaliacao_CEFET-BA_versao_final.pdf

12. Cardoso RJ. Egressos do Centro de Graduação em Enfermagem da Faculdade de Medicina do Triângulo Mineiro: sua formação e trajetória profissional [tese]. Ribeirão Preto: Escola de Enfermagem de Ribeirão Preto, Universidade de São Paulo; 2002.

13. Ghiorzi AR, Ribeiro EM, Fenilli RM. O currículo, o curso e a profissão, na visão de egressos da graduação em enfermagem da UFSC. Texto Contexto Enferm. 1995; 4(n.esp):69-91.

14. Soler ZASG, Perroca MG, Santos MLSG, Santos MR. Inserção dos egressos do curso de graduação em enfermagem da Faculdade de Medicina de São José do Rio Preto no mercado de trabalho: parâmetros para a qualidade do ensino. Acta Paul Enferm. 2001;14(1):37-47.

15. Oliveira BRG, Schneider JF, Rizzotto MLF, Rodrigues RM. Avaliação e construção de um projeto político pedagógico para a graduação em enfermagem. Rev Bras Enferm. 2003;56(4):369-73.

16. Oliveira RP, Souza SZ. Programa de estudo sobre o destino profissional de graduados pela USP [projeto de pesquisa]. São Paulo: Centro de Estudos e Pesquisas em Políticas Públicas de Educação, Faculdade de Educação, Universidade de São Paulo; 2004. 